ORIGINAL ARTICLE

\title{
Comparison of fatalities from work related motor vehicle traffic incidents in Australia, New Zealand, and the United States
}

\author{
T Driscoll, S Marsh, B McNoe, J Langley, N Stout, A-M Feyer, A Williamson
}

Injury Prevention 2005;11:294-299. doi: 10.1136/ip.2004.008094

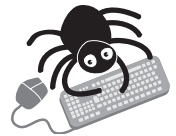

Tables 3 and 4 can be viewed on our website.

See end of article for authors' affiliations

........................

Correspondence to Dr T Driscoll, ELMATOM Pty Ltd and School of Public Health, University of Sydney, Australia, 49 Taleeban Road, Riverview NSW 2066, Australia; elmatom@optushome.com. au

Accepted 13 March 2005
Objective: To compare the extent and characteristics of motor vehicle traffic incidents on public roads resulting in fatal occupational injuries in Australia, New Zealand (NZ), and the United States (US).

Design and setting: Information came from separate data sources in Australia (1989-92), NZ (1985-98), and the US (1989-92).

Methods: Using data systems based on vital records, distributions and rates of fatal injuries resulting from motor vehicle traffic incidents were compared for the three countries. Common inclusion criteria and occupation and industry classifications were used to maximize comparability.

Results: Motor vehicle traffic incident related deaths accounted for 16\% (NZ), 22\% (US), and 31\% (Australia) of all work related deaths during the years covered by the studies. Australia had a considerably higher crude rate (1.69 deaths/100 000 person years; 95\% confidence interval (95\% Cl) 1.54 to 1.83 ) compared with both $\mathrm{NZ}(0.99 ; 95 \% \mathrm{Cl} 0.85$ to 1.12$)$ and the US $(0.92 ; 95 \% \mathrm{Cl} 0.89$ to 0.94$)$. Industry distribution differences accounted for only a small proportion of this variation in rates. Case selection issues may have accounted for some of the remainder, particularly in NZ. In all three countries, male workers, older workers, and truck drivers were at higher risk.

Conclusions: Motor vehicle traffic incidents are an important cause of work related death of workers in Australia, NZ, and the US. The absolute rates appear to differ between the three countries, but most of the incident characteristics were similar. Lack of detailed data and inconsistencies between the data sets limit the extent to which more in-depth comparisons could be made.
S tudies in several countries suggest that vehicle related fatal incidents on public roads ("traffic incidents") are an important component of all work related deaths. ${ }^{1-5}$ Traffic incidents affect workers in many occupations including those who routinely drive as part of their job (for example, truck and taxi drivers) and those who only occasionally drive as part of their job (for example, farmers, teachers, nurses). In addition, employees across all occupations are exposed to the risk of traffic crashes as they commute between work and home.

The results of a comparison of fatal work related injuries in the United States (US), Australia, and New Zealand (NZ) were recently reported. ${ }^{67}$ As discussed in these earlier papers, such comparisons can offer a better understanding of the work related hazards and risks in each of the comparison countries, provide insights into more general issues associated with these fatal events, and assist with the planning of prevention initiatives. Comparative studies also help to develop an improved understanding of the merits of various approaches to data collection, analysis, and interpretation, and can be a prompt for action in countries that have relatively higher fatality incidence rates.

The published comparisons excluded deaths related to traffic incidents because information was not available for NZ workers. New Zealand data on work related traffic deaths have since been collected, allowing comparison of the deaths in Australia, NZ, and the US. The present paper describes the results of this comparison.

\section{METHODS}

\section{Data sources}

The method was modeled on that used in the earlier international comparison. ${ }^{6}$ Data on work related deaths from
Australia and NZ came from purpose specific studies based on coroners' data, because neither Australia nor NZ routinely collect detailed information on work related deaths, and death certificates in both countries do not have a field that identifies a death as work related. Data from the US came from the National Traumatic Occupational Fatalities surveillance system (NTOF), based on data obtained directly from death certificates (on which there is a specific field that identifies death as work related). Each system provides a census of work related deaths for their respective countries. Methodology, strengths and weaknesses of, and main results from each of the source studies have been described in detail elsewhere. ${ }^{38-13}$

Besides workplace deaths (workers killed in work related events that did not involve traffic incidents on public roads), the Australian (1989-92 inclusive) and NZ (1985-98 inclusive) data also included deaths of workers traveling for work purposes (work road deaths) and to or from work (commuting deaths), and non-worker deaths that occurred as a result of traffic incidents involving a working vehicle on a public road (road bystander deaths). Conversely, data from the US, available from 1980 to 2001, only included workplace and work road cases. Therefore, bystander and commuting deaths are not considered in this report. Because 1989-92 were the years common to all three data sets, data for Australia and the US were limited to this period. Because of the relatively small number of work related deaths in New Zealand, all 14 years of NZ data (1985-98) were used to maximize the reliability of the estimates. Although more recent data would have been better, neither Australia nor NZ routinely collect information on work related deaths, and no more recent data were available for these countries. Cause of death information in all three data sets was coded to the external cause 
Table 1 Percentage distribution and rate of fatally injured workers by industry division and overall. Crude and standardised rates

\begin{tabular}{|c|c|c|c|c|c|c|c|c|c|}
\hline \multirow[b]{2}{*}{ Industry division } & \multicolumn{3}{|c|}{ Australia* (n $=521$ ) } & \multicolumn{3}{|c|}{ New Zealand ${ }^{*}(n=210)$} & \multicolumn{3}{|c|}{ United States* ( $n=4322$ ) } \\
\hline & Rate† & $(95 \% \mathrm{Cl}) \ddagger$ & $\begin{array}{l}\text { Total } \\
\% \S\end{array}$ & Rate & $(95 \% \mathrm{Cl})$ & Total \% & Rate & $(95 \% \mathrm{Cl})$ & Total \% \\
\hline Agriculture, forestry (including logging), and fishing & 1.84 & $(1.25-2.61)$ & 7.8 & 0.91 & $(0.54-1.42)$ & 4.0 & 2.69 & $(2.42-2.96)$ & 13.3 \\
\hline Mining & 3.40 & $(1.81-5.81)$ & 9.4 & 1.50 & $(0.0-8.4)$ & 3.7 & 3.06 & $(2.42-3.70)$ & 12.2 \\
\hline Construction & 1.74 & $(1.24-2.38)$ & 16.8 & 1.51 & $(0.92-2.34)$ & 9.8 & 2.11 & $(1.94-2.28)$ & 16.9 \\
\hline Manufacturing & 0.54 & $(0.35-0.79)$ & 17.8 & 0.14 & $(0.04-0.32)$ & 2.9 & 0.39 & $(0.35-0.43)$ & 13.4 \\
\hline Transport, storage, communications, and public utilities & 10.15 & $(8.91-11.4)$ & 62.7 & 6.99 & (5.67-8.52) & 43.3 & 4.57 & $(4.34-4.80)$ & 44.6 \\
\hline Wholesale and retail sales & 0.95 & $(0.73-1.22)$ & 52.7 & 0.48 & $(0.29-0.76)$ & 30.0 & 0.49 & $(0.45-0.53)$ & 17.9 \\
\hline Finance/insurance/real estate/services & 0.64 & $(0.50-0.81)$ & 37.0 & 0.32 & $(0.21-0.48)$ & 21.3 & 0.27 & $(0.25-0.29)$ & 20.5 \\
\hline Public administration & 1.36 & $(0.82-2.13)$ & 43.7 & 0.80 & $(0.32-1.65)$ & 67.5 & 1.38 & $(1.23-1.53)$ & 38.1 \\
\hline Unknown & & & 22.2 & & & 46.9 & & & 20.8 \\
\hline $\begin{array}{l}\text { Total } \\
\text { Standardised rater }\end{array}$ & 1.69 & $(1.54-1.83)$ & 30.9 & 0.99 & $(0.85-1.12)$ & 16.2 & 0.92 & $(0.89-0.94)$ & 22.1 \\
\hline \multicolumn{10}{|c|}{$\begin{array}{l}\text { *Data for Australia and the US were from 1989-92; data for NZ were from 1985-98. } \\
\text { †Deaths per } 100000 \text { person years. } \\
\text { 995\% confidence interval. } \\
\text { \$Motor vehicle deaths as a percentage of all deaths for the industry group. } \\
\text { - Standardised to the Australian industry distribution. }\end{array}$} \\
\hline
\end{tabular}

codes (E-codes) from the International Classification of Diseases, Ninth Revision (ICD-9)..$^{14}$

\section{Data comparability}

As each country used different case criteria, the study populations in all three countries were different. Therefore, for this comparison, it was necessary to define a population of interest that was common to all three data sets. In addition, the level of detailed information for cases differed between countries. Along with specific inclusion criteria, other steps were taken to harmonize the data to ensure maximum comparability. Main inclusion criteria were:

- unintentional death resulting from a motor vehicle incident on a public road (E-codes between E810 to E819 inclusive);

- incident occurring while working;

- age within 16-84 years inclusive;

- employed within the civilian labor force; and

- died within one year of the incident.

Although cases were identified by their assigned E-code, information for the Australian data indicated that the assigned E-codes were incorrect for a small proportion of deaths. This meant that, for Australia, nine fewer deaths were included ( 25 deaths that met the E-code criterion were excluded, and 16 deaths with an E-code outside this range were included). Excluded deaths were primarily motor vehicle incidents that clearly had not occurred on a public road. Similar E-code comparison information was not available for NZ or the US.

Self employed people and unpaid family helpers working in a family business were included, but military personnel, volunteers, students, and unpaid domestic workers were excluded. Deaths judged as suicides or homicides were not within the range of the motor vehicle E-codes and were also excluded. Traffic incidents not involving a motor vehicle (for example, a bicycle courier colliding with a power pole) were also excluded because those that occurred on public roads could not be uniquely identified. To improve comparability, occupation and industry codes were grouped into broad categories.

Denominator data used to calculate rates came from quarterly labour force surveys conducted by the Australian Bureau of Statistics, ${ }^{15} \mathrm{NZ}$ census data, ${ }^{16}$ and monthly household surveys from the United States Bureau of Labor
Statistics. ${ }^{17}$ Adjustments made to the occupation and industry classifications in the numerator data were also made to the denominator data.

\section{Analysis}

Where appropriate, rates per 100000 person years were reported; 95\% confidence intervals (95\% CI) were calculated assuming a Poisson distribution. Industry standardised rates (standardized to the Australian industry distribution) were calculated using direct standardization. ${ }^{18}$ Overall rates are reported as standardized and crude (unadjusted). All other presented rates are crude.

\section{RESULTS}

The inclusion criteria were met by 521 work related motor vehicle traffic deaths in Australia, 210 traffic deaths in NZ, and 4322 traffic deaths in the US. Based on information from the initial comparison 6 and this study, work related motor vehicle traffic deaths comprised $31 \%$ of all Australian worker deaths, $16 \%$ of NZ worker deaths (this was based only on deaths from 1985-94 inclusive, because the NZ study on workplace deaths ${ }^{11}$ only covered those years), and $22 \%$ of all US worker deaths. Australia (1.69 deaths/100 000 person years; $95 \%$ CI 1.54 to 1.83 ) had a much higher unadjusted fatality rate than both NZ $(0.99 ; 95 \%$ CI 0.85 to 1.12$)$ and the US $(0.92 ; 95 \%$ CI 0.89 to 0.94$)$. Most of this difference remained after rates were standardized by industry, with the Australian rate $50 \%$ higher than the standardized NZ rate and $60 \%$ higher than the standardized US rate (table 1 ).

For both Australia and the US, there was a general downward trend in rates for the period 1989-92 inclusive (fig 1). In NZ, rates were more scattered and had large confidence intervals, and a definitive trend was less evident.

In all three countries, males accounted for $92 \%$ to $93 \%$ of deaths and had a rate 9-10 times that of the female rate. About $70 \%$ of the traffic deaths were among people aged 25-54 years old, with the largest proportion between 25 and 34 years. Although rates were highest in the oldest age group in all three countries, rates for those 20-24 years old and 25-34 years old in Australia were markedly higher. In addition, rates in those aged 65 years and above were particularly high in Australia (fig 2).

Similar high risk industries were identified in all three data sets. Transport, storage, communications, and public utilities (hereafter called "the transport industry" for ease of expression) had the highest rate in all three countries, with one third to one half of all work related motor vehicle deaths 


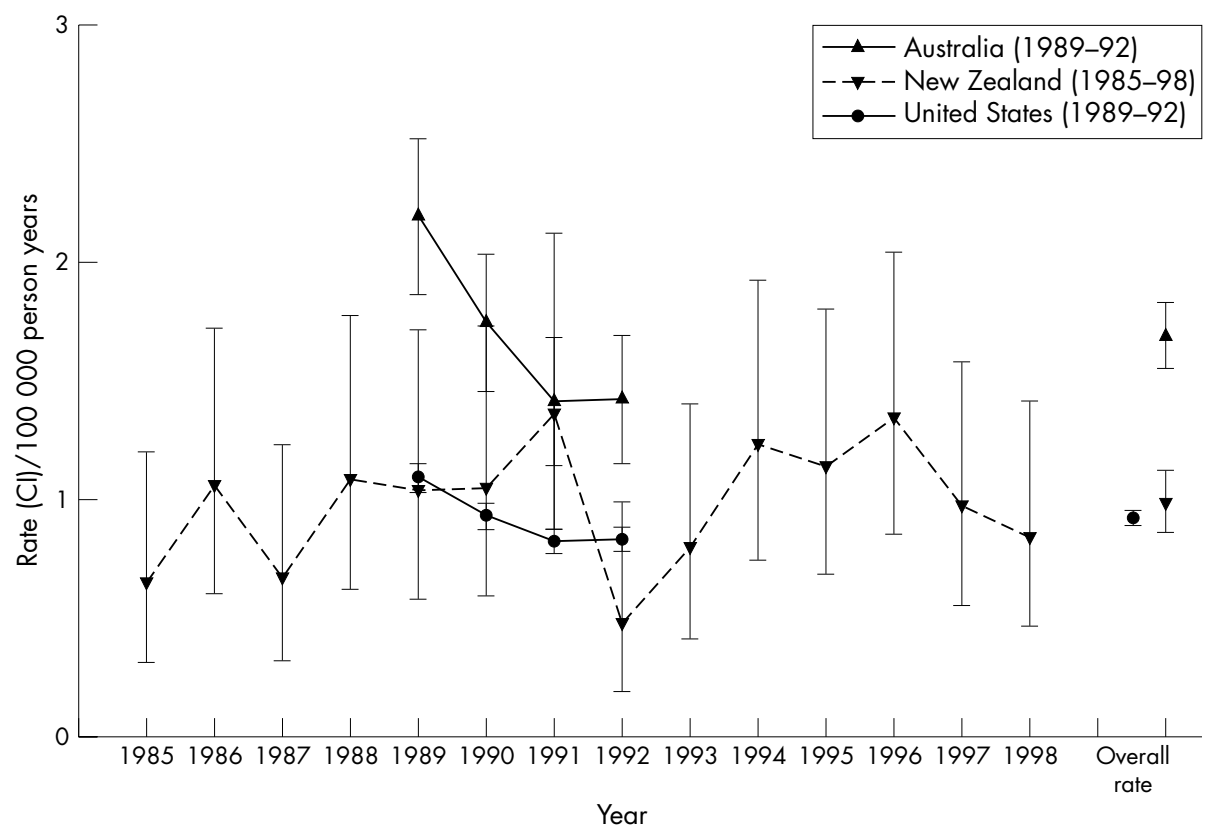

Figure 1 Crude rates of fatal work related motor vehicle traffic injuries in Australia, New Zealand, and the United States.

in Australia and NZ falling into this category. The vast majority of workers in this group (both those killed and those employed) were employed in the transport industry. Mining, agriculture (including logging, other forestry work, and fishing) and construction had the next highest rates in all three countries. Apart from the transport industry, only the mining industry in Australia, and only the construction industry in NZ, had rates considerably above their respective country's average rate, whereas in the US, rates for five of the highest risk industries were at least 1.5 times that of the average rate for the US. There was also considerable variation between countries in terms of motor vehicle deaths as a percentage of all deaths for specific industry groups (table 1).

In Australia and NZ, the broad occupation group trades workers, operators, and labourers, which includes truck

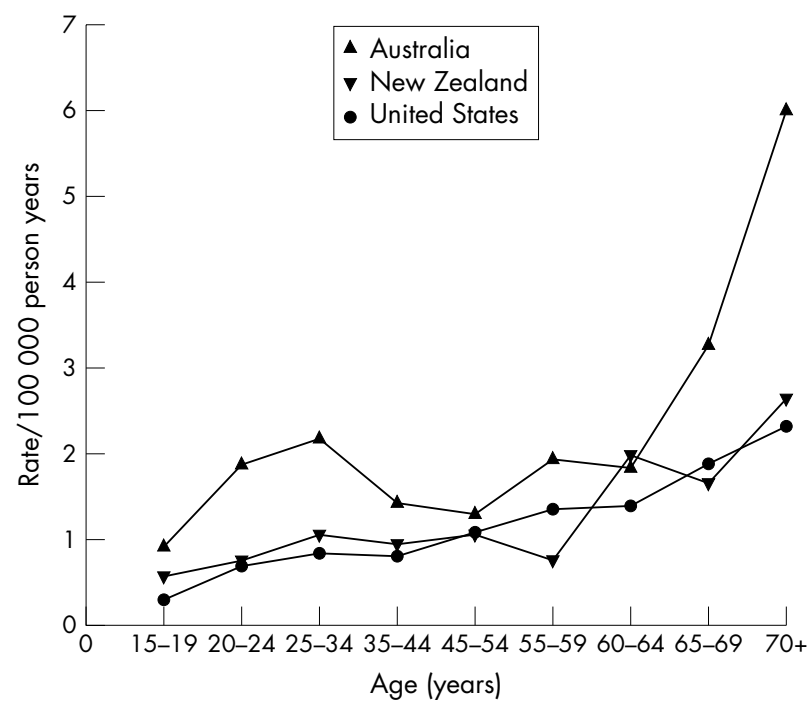

Figure 2 Age specific rates of fatal work related motor vehicle traffic injuries in Australia, New Zealand, and the United States. drivers, had, by far, the highest fatality rate, whereas in the US the rate for this group was similar to that for farming, forestry, and fishing workers. Although farming, forestry, and fishing workers had the next highest rate in each country, only in the US was the rate for this group considerably higher than the average rate. Similar to industry, there was considerable variation between countries in terms of motor vehicle deaths as a percentage of all deaths for specific occupations (table 2).

Driving related occupations and other selected occupations with relatively high numbers of deaths in each country were examined in further detail. Not surprisingly, driving occupations accounted for a large proportion of all traffic deaths in each country. Truck drivers had a very high rate of death and accounted for $37 \%$ (NZ and US) to $49 \%$ (Australia) of all work related motor vehicle deaths. The US fatality rate (15.4 deaths per 100000 person years; 95\% CI 14.6 to 16.2) was considerably lower than both the Australian 35.0; 95\% CI 29.8 to 38.2$)$ and NZ $(27.5 ; 95 \%$ CI 21.8 to 34.2$)$ rates for truck drivers. Although police officers also had a rate considerably above the average rate in Australia (8.30; 95\% CI 4.57 to 13.9 ) and the US $(5.87 ; 95 \%$ CI 4.87 to 6.87$)$, NZ traffic deaths did not include any police officers.

The type of traffic incident, as indicated by the E-code, was broadly similar. The most common incident types in each country were collisions between two motor vehicles, loss of control of a motor vehicle without collision, and motor vehicle collision with a pedestrian. The US had much higher proportions of incidents resulting in the death of a pedestrian (16.1\%; Australia 9.6\%; NZ 6.7\%), but some of the US proportions may have been biased downwards because of the relatively high proportion of deaths for which the type of incident was unspecified (see http://www.injuryprevention. com/supplemental for table 3 ).

In terms of the E-codes describing the role of the deceased person, the US had a much higher proportion of pedestrian deaths, consistent with the E-codes for the type of traffic incident. The US also had a considerably lower proportion of deaths of drivers and motorcyclists than either Australia or NZ. However, this apparent difference may have been biased by the high percentage ( $18 \%$ ) of US deaths where the role of the 
Table 2 Percentage distribution and crude rate of fatally injured workers by occupation group

\begin{tabular}{|c|c|c|c|c|c|c|c|c|c|}
\hline \multirow[b]{2}{*}{ Occupation division } & \multicolumn{3}{|c|}{ Australia $^{*}(n=521)$} & \multicolumn{3}{|c|}{ New Zealand* $(n=210)$} & \multicolumn{3}{|c|}{ United States* $(n=4322)$} \\
\hline & Rate† & $(95 \% \mathrm{Cl}) \ddagger$ & Total \%§ & Rate & $(95 \% \mathrm{Cl})$ & Total \% & Rate & $(95 \% \mathrm{Cl})$ & Total \% \\
\hline Managers, professionals, and technicians & 0.90 & $(0.71-1.13)$ & 31.2 & 0.46 & $(0.32-0.65)$ & 22.0 & 0.35 & $(0.32-0.38)$ & 18.6 \\
\hline Clerical & 0.21 & $(0.10-0.37)$ & 57.4 & 0.17 & $(0.06-0.40)$ & 34.2 & 0.18 & $(0.15-0.21)$ & 33.3 \\
\hline Sales and service Workers & 0.63 & $(0.39-0.85)$ & 58.0 & 0.47 & $(0.25-0.80)$ & 25.7 & 0.48 & $(0.44-0.52)$ & 19.8 \\
\hline Farming, forestry, and fishing workers & 1.90 & $(1.19-2.55)$ & 8.1 & 0.83 & $(0.48-1.33)$ & 4.3 & 2.18 & (1.93-2.43) & 11.6 \\
\hline Trades workers, operators, and labourers & 3.35 & (3.04-3.73) & 37.5 & 2.17 & $(1.81-2.53)$ & 22.6 & 2.22 & $(2.14-2.30)$ & 25.6 \\
\hline Unknown & & & 63.2 & & & 9.0 & & & 24.7 \\
\hline Total & 1.69 & $(1.54-1.83)$ & 30.8 & 0.99 & $(0.85-1.12)$ & 16.2 & 0.92 & $(0.89-0.94)$ & 22.1 \\
\hline
\end{tabular}

person was unspecified (see http://www.injuryprevention. com/supplemental for table 4).

\section{DISCUSSION}

The rate of work related motor vehicle traffic deaths was considerably higher in Australia than in NZ or the US. Unlike the earlier comparison between the three countries, ${ }^{6}$ which did not include traffic incidents on public roads, only a small proportion of this difference was due to differences in industry distribution. Two key questions arise from this finding. Are the differences real or the result of methodologic factors (that is, bias)? If the differences are real, why do they arise?

The most likely source of bias is under enumeration of cases in NZ and the US. Studies have suggested the NTOF underestimates all fatal work related injuries by $10 \%$ to $30 \%{ }^{3}{ }^{13}{ }^{19-21}$ For traffic deaths, case identification may be even more problematic, resulting in larger underestimates of fatalities. Because of insufficient information, the NZ study was unable to classify as work related or not (and therefore excluded) about $37 \%$ of all traffic related deaths because of insufficient information about the purposes of travel. In contrast, the Australian study could not classify (and so excluded) about $7 \%$ of all injury deaths for the same reason. Some of these Australian and NZ deaths that could not be classified would have been work related, leading to an underestimation of the true rate of work related motor vehicle traffic deaths. The proportion of unclassifiable deaths that were truly work related is not known. However, in the absence of other information, both the Australian and NZ studies classified deaths involving drivers of large trucks as work related. Therefore, the proportion of unclassifiable deaths that were work related can be expected to be not more, and most likely less, than the proportion of classifiable deaths that were work related, but the extent of the likely variation is not known. If the unclassifiable deaths are allocated as work related or not work related based on the distribution in the classifiable deaths (and that the US had a $30 \%$ under enumeration), the true industry adjusted rate per 100000 person years would be about 1.82 for Australia, 1.79 for NZ, and 1.52 for the US. If the work related rate for unclassifiable deaths was half that of classifiable deaths (and the US had a 15\% under enumeration), the true industry adjusted rates would be about 1.75 (Australia), 1.46 (NZ), and 1.29 (US). This suggests that under enumeration (which occurs to an unknown extent in all three countries) probably accounts for some, but not all, of the difference in rates between the three countries. Supporting the conclusion that Australia does have the highest death rate is the finding that the rate of truck driver death-an indicator that is least likely to be affected by missing data-was highest in Australia, and markedly so compared with the US. Finally, the difference in fatality rates between Australia and the other two countries is not due simply to an increased number of night-time deaths, as the Australian rates were higher at all times of the day and night.

The cause of the remaining differences in the rates between the three countries is not entirely clear. Undoubtedly, factors like the type, location, and maintenance of roads and road surfaces; speed limits; traffic volumes; and the type, age, and maintenance of vehicles are likely to play a role in determining differences in road safety between countries. However, these factors are likely to be reflected in the allvehicle fatality rates. From 1991-95, all-vehicle fatality rates in the three countries show clear differences from the pattern shown in this study for work related motor vehicle fatalities. During this period, in terms of all-vehicle fatality rates per 10000 registered vehicles, NZ (2.7) had the highest rate, followed by the US (2.1), and Australia (1.9). For all vehicle fatality rates per 100 million kilometres traveled, the US rate was highest (2.7), compared with NZ (2.0) and Australia (1.2). ${ }^{22-25}$

This suggests that the risk factors for work related crashes may differ between countries for reasons different than those for non-work related crashes. An Australian benchmarking study of truck safety attempted to explain differences between fatal truck crash rates between several countries with good road safety records. The study concluded that the lower amount of divided and limited access roads and higher speed limits for trucks were the most likely explanations for higher fatal truck crash rates for Australia compared with the US. ${ }^{26}$ A more in-depth comparative analysis, which would require more detailed data, is needed to further explain the differences between traffic deaths in the three countries.

Occupation and industry serve as rough proxy measures of hazard and risk. High risk occupation and industry groups were similar in the three countries. However, the US had a larger number of industries with above average rates. Truck drivers had particularly high rates in each country. The probability of being fatally injured in a traffic incident while at work is related to the time exposed to hazards (that is, the time spent traveling on public roads for work purposes) and the risk associated with those exposures (which is determined by factors such as the vehicle being used, the type of roads, traffic conditions, work schedules, and so on). Therefore, it is not surprising that driving occupations account for a large proportion of all work related motor vehicle traffic deaths, and that truck drivers in particular have the highest rates. Notwithstanding this, the rate for truck drivers was extremely high, both in relation to the overall rate of traffic deaths and the overall rate of non-traffic deaths (per 100000 person years) - 3.8 in Australia, 4.9 in $\mathrm{NZ}$, and 3.2 in the US. ${ }^{6}$ 
Some differences in occupation and industry may be due, in part, to differences in case definitions. For Australia and $\mathrm{NZ}$, occupation and industry are based on the activity at the time of the incident; in the US, this information is based on the "usual" or lifetime occupation and industry. For the US, this may have resulted in cases being misclassified. This was confirmed in a study on machine related fatalities in the construction industry. Death certificates for a high percentage $(66 \%)$ of workers 55 years and older noted that the decedent worked in the construction industry but was involved in a tractor related farm incident. ${ }^{27}$ Although this does affect comparisons of industry and occupation, this should not affect the coding of work relatedness or the overall rates of work related death.

The relation of traffic injury death rates to sex and age was similar between countries and was also similar to that seen for workplace deaths-much higher rates for males than females, and rates that increased with age, and were highest in the older age groups. One noticeable difference was that Australian rates for people aged 65 and over were proportionately and absolutely much higher than corresponding rates in NZ and the US. Australia also had high rates for workers in their twenties and thirties, a pattern not usually seen for workplace deaths, ${ }^{3911}$ but consistent with increased fatality rates in young drivers in general. These age and sex relations for rates of fatal traffic injuries have been reported for all traffic fatalities (not just work related motor vehicle traffic fatalities)..$^{28} 29$

The possible influence on age related rate changes of other factors that might increase risk (such as occupation) could not be assessed in detail because the number of deaths in Australia and NZ was too low. The information that was available showed that farmers and motor vehicle operators were the two largest occupation groups involved in each of the countries. The cause of the particularly high Australian rates (relative to NZ and the US) in older workers is not clear. As the proportion of all work related motor vehicle traffic deaths that involved those 65 years or over was not higher in Australia (people 65 years and above made up a higher proportion of the deaths in the US $(6.2 \%)$ than in either NZ $(3.8 \%)$ or Australia $(3.2 \%))$, the possibility is raised of under enumeration in the denominator. The data on working status for this study were collected through different mechanisms for cases (working status based on the circumstances of the fatal incident) than for population data (working status based on self report) in all three countries. It is conceivable that for financial or other reasons an older person who performs work occasionally would report in a government survey that they are actually retired. However, the extent to which this may occur, and whether this would be more of a problem in Australia than elsewhere, is not known, and there are no data currently available to support or refute this possibility.

The US had a much higher proportion of traffic deaths involving pedestrians who were working. The reason for this difference is not apparent from the available data. A high proportion of pedestrian fatalities in the US construction industry has been reported (based on NTOF data from 198092),,$^{30}$ but in the current study all three countries had construction as the first or second most common industry of employment of workers killed in pedestrian incidents. Although the US also had lower proportions of traffic deaths related to motor vehicle collision, motor vehicle incidents due to loss of control without collision, and traffic incidents involving the death of drivers, much of the difference is probably the result of the higher proportion of US deaths in which relevant information was unspecified.
While highlighting the similarities between the three countries, this study also underscores the difficulties of indepth comparisons that require detailed information beyond what is currently available. As mentioned earlier, although recent data are more appropriate for studies such as this, neither Australia nor NZ routinely collect detailed information on work related deaths. Thus, comparisons for this study were based on individual studies that are only undertaken on an irregular basis. Reviews of recently published fatality rates for all three countries indicated a decline in general motor vehicle fatality rates. By 2002, the average population based rate for 1989-92 dropped about 35\% in Australia, 48\% in NZ, and $15 \%$ in the US. ${ }^{23}{ }^{25} 31$ Whether the work related motor vehicle deaths would have dropped to a similar extent is not known. Although work related trend data are not available for Australia and NZ, data from the US actually showed an increase in work related motor vehicle fatalities from 1992 through $2001 .{ }^{32}$

These results reinforce the fact that motor vehicle crashes are an important cause of work related death. However, there is much about these incidents that is not known and therefore much scope for research. General research requirements in this area have recently been well summarized elsewhere, ${ }^{33} 34$ and include better assessment and evaluation (of existing work organization and safety interventions), improvement to data systems (inclusion of appropriate variables, particularly in systems focused on occupational injury), and a focus on fatigue (assessment, quantification, design, and evaluation of interventions) and use of electronic equipment such as cell phones while driving. Improvements in data systems, in particular, would enhance international comparisons such as the one reported here. For Australia, the high fatality rate in older people also warrants attention.

\section{CONCLUSIONS AND IMPLICATIONS FOR PREVENTION}

Driving is a common activity in many occupations. The results presented in this paper suggest that the characteristics of work related motor vehicle traffic deaths in Australia, NZ, and the US are similar. They also suggest that many of the hazards associated with driving for work are similar in the three countries. Detailed information regarding the incidents would allow a more in-depth comparison of the circumstances surrounding the incidents and identification of factors that might be appropriate targets for injury prevention efforts.

\section{Key points}

- Compared with New Zealand and the United States, the industry adjusted Australian rate of work related motor vehicle traffic death was $50 \%$ to $60 \%$ higher.

- Industry distribution differences and case selection issues may account for some of this difference, particularly in New Zealand.

- The characteristics of the incidents and involved workers were qualitatively similar in the three countries.

- In all three countries males, older workers, and truck drivers had a high rate of work related motor vehicle traffic death.

- Improvements to the available data would allow a more in-depth comparison of such incidents. 


\section{ACKNOWLEDGEMENTS}

Funding for this project was provided by the National Institute for Occupational Safety and Health. The authors wish to thank Mr Shaun Stephenson for assistance with providing denominator data for New Zealand. The Australian data come from a study of all work related fatalities conducted by the National Occupational Health and Safety Commission. The authors wish to acknowledge the International Collaboration Effort (ICE) on injury statistics for contributions to this research. The ICE is sponsored by the National Centre for Health Statistics, US Centers for Disease Control and Prevention, with funding from the National Institute of Child Health and Development, National Institutes of Health. The views in this publication are those of the authors.

\section{Authors' affiliations}

T Driscoll, ELMATOM Pty Ltd and School of Public Health, University of Sydney, NSW, Australia

S Marsh, N Stout, National Institute for Occupational Safety and Health, Morgantown, WV, USA

B McNoe, J Langley, Injury Prevention Research Unit, Department of Preventive and Social Medicine, University of Otago, New Zealand A-M Feyer, Department of Preventive and Social Medicine, University of Otago, New Zealand; and Health Advisory Practice,

PriceWaterhouseCoopers

A Williamson, NSW Injury Risk Management Research Centre, University of New South Wales, Australia

The findings and conclusions in this report are those of the authors and do not necessarily represent the views of the National Institute for Occupational Safety and Health.

\section{REFERENCES}

1 Harrison J, Mandryk J, Frommer M. Work-related road fatalities in Australia, 1982-1984. Accid Anal Prev 1993;25:443-51.

2 Loomis D, Richardson D, Wolf $S$, et al. Fatal occupational injuries in a southern state. Am J Epidemiol 1997;145:1089-99.

3 Marsh S, Layne A. Fatal injuries to civilian workers in the United States, 19801995: national profile. 2001, National Institute for Occupational Safety and Health: Cincinnati, Ohio.

4 Pratt S. Work-related roadway crashes-United States, 1992-2002. Morb Mortal Wkly Rep 2004;53:260-4.

5 Rossignol M, Pineault M. Fatal occupational injury rates: Quebec, 1981 through 1988. Am J Public Health 1993;83:1563-6.

6 Feyer AM, Williamson AM, Stout $N$, et al. Comparison of work related fatal injuries in the United States, Australia, and New Zealand: method and overall findings. Inj Prev 2001;7:22-8.

7 Williamson A, Feyer A, Stout $N$, et al. Use of narrative analysis for comparisons of the causes of fatal accidents in three countries: New Zealand, Australia, and the United States. Inj Prev 2001 ; (Suppl 1):i15-20.

8 Anonymous. Fatal occupational injuries-United States, 1980-1994. Morb Mortal Wkly Rep 1998;47:298-303.

9 Driscoll T, Mitchell R, Mandryk J, et al. Work-related fatalities in Australia, 1989 to 1992: an overview. Journal of Occupational Health and SafetyAustralia and New Zealand 2001;17:45-66.

10 Mitchell R, Driscoll T, Healey S. Work-related road fatalities in Australia. Accid Anal Prev 2004;36:851-60.

11 Feyer AM, Langley J, Howard M, et al. The work-related fatal injury study: numbers, rates and trends of work-related fatal injuries in New Zealand 1985-1994. N Z Med J 2001;114:6-10.
12 Langley J, Feyer A-M, McNoe B. Work-related fatal traffic injuries in New Zealand 1985-1998. 2003, Injury Prevention Research Unit, New Zealand Environmental and Occupational Health Research Centre: Dunedin.

13 Stout N, Jenkins E, Pizatella T. Occupational injury mortality rates in the United States: changes from 1980 to 1989. Am J Public Health 1996:86:73-7.

14 World Health Organisation, International Classification of Diseases. Manual of the International Statistical Classification of Diseases, Injuries and Causes of Death. 9th Revision. Volume one. 1977, Geneva: WHO.

15 Australian Bureau of Statistics. Labour Statistics Australia, 1992. 1993, ABS: Canberra.

16 Statistics New Zealand. Census of Population \& Dwellings, 1986, 1991, 1996. 1992, Statistics New Zealand: Wellington. Available at http:// www.stats.govt.nz/census/default.htm (accessed 2002).

17 Bureau of Labor Statistics. Labor force, employment, and unemployment from the current population survey, in BLS Handbook of Methods. US Department of Labor, Bureau of Labor Statistics: Washington, DC, 1992:3-12.

18 Checkoway H, Pearce N, Crawford-Brown D. Research methods in occupational epidemiology. 1989, Oxford: Oxford University Press.

19 Biddle EA, Marsh SM. Comparison of two fatal occupational injury surveillance systems in the United States. J Safety Res 2002;33:337-54.

20 Layne L. Occupational injury mortality surveillance in the United States: an examination of census counts from two different surveillance systems, 19921997. Am J Ind Med 2004:45:1-13.

21 Stout N, Bell C. Effectiveness of source documents for identifying fatal occupational injuries: a synthesis of studies. J Public Health 1991;81:725-8.

22 National Highway Traffic Safety Administration. Traffic Safety Facts 1993 State traffic data. 1993, NHTSA: Washington, DC. Available at http:// www-nrd.nhtsa.dot.gov/pdf/nrd-30/NCSA/TSF93/std93.pdf laccessed 2004).

23 New Zealand Land Transport Safety Authority. Motor vehicle crashes in New Zealand. LTSA: Wellington, 2002. Available at http://www.ltsa.govt.nz/ research/annual-statistics-2002/docs/historical-table-1.pdf (accessed 2004).

24 New Zealand Land Transport Safety Authority. Media release: 5,000 killed on New Zealand roads in past ten years - Estimated statistic. LTSA Wellington, 2004. Available at http://www.ltsa.govt.nz/media/2004/ 040101.html (accessed 2004).

25 Australian Transport Safety Bureau. Road crash data and rates. Australian States and Territories 1925 to 2002. ATSB: Canberra, 2003. Available at $\mathrm{http}$ ///www.atsb.gov.au/road/stats/pdf/crash_rates_2003.pdf (accessed 2004).

26 Haworth N, Vulcan P, Sweatman P. Truck safety benchmarking study. 2002, National Road Transport Commission: Canberra.

27 Pratt S, Kisner S, Moore P. Machinery-related fatalities in the construction industry. Am J Ind Med 1997;32:42-50.

28 Massie D, Campbell K, Williams A. Traffic accident involvement rates by driver age and gender. Accid Anal Prev 1995;27:73-87.

29 Massie D, Green P, Campbell K. Crash involvement rates by driver gender and the role of average annual mileage. Accid Anal Prev 1997;29:675-85.

30 Ore T, Fosbroke D. Motor vehicle fatalities in the United States construction industry. Accid Anal Prev 1997;29:613-26.

31 National Highway Traffic Safety Administration. Traffic Safety Facts 2003. State traffic data. NHTSA: Washington, DC, 2004. Available at http://wwwnrd.nhtsa.dot.gov/pdf/nrd-30/NCSA/TSFAnn/TSF2003EarlyEdition.pdf (accessed 2004).

32 National Institute for Occupational Safety and Health. Work-related roadway crashes: who's at risk? 2004, Department of Health and Human Services, Centers for Disease Control and Prevention, National Institute for Occupational Safety and Health: Cincinnati, $\mathrm{OH}$.

33 National Road Transport Commission. National heavy vehicle safety strategy. 2003-2010. NRTC: Canberra, 2003. Available at http://twu.com.au/ downloads/NHVSS20032010.pdf (accessed 2004).

34 Pratt S. Work-related roadway crashes. Challenges and opportunities for prevention, in NIOSH Hazard Review. 2003, Department Of Health And Human Services, Centers for Disease Control and Prevention, National Institute for Occupational Safety and Health: Cincinnati, $\mathrm{OH}$ 